\title{
Consumer Preferences for Mobile Carriers in Tanzania: A Case of Group, Family, Age and Gender
}

\author{
Justinian Anatory \\ School of Informatics \\ The University of Dodoma, \\ Dodoma, Tanzania.
}

\begin{abstract}
This paper investigates age, family, group and gender influence consumer preference for selection of the mobile carrier. About seventy seven students from high learning institutions in Dodoma Municipality participated in responding to prepared questionnaires. The results indicate that family members and friends are contributing in influencing consumer preferences to select mobile services provider, although at smaller margins. This paper revealed also that there is no direct relationship between selection of a mobile carrier and age or gender.
\end{abstract}

\section{General Terms}

Selection of mobile operator, factors influence customer buying behaviour

\section{Keywords}

Family, Gender, Age, Group, mobile operators' selection, mobile carriers, customer buying behavior.

\section{INTRODUCTION}

In today's complex business environment, it has become very crucial for companies to attract and retain customers for longterm sustainable growth. Just like companies of other business domain, Mobile carriers also consider their customer to be the most important assert [1]. In the past few years, Tanzania mobile sector has witnessed a rapid and substantial growth. From 2000, the growth of mobile sector has real picked up tremendously. The growth of mobile sector in Tanzania can be proved when we look at the mobile subscription since 2000 and today as shown in table 1 . The current mobile carriers with at least coverage in all Tanzania cities/town include Vodacom Tanzania [2], Tigo Tanzania [3], Airtel Tanzania [4] and Zantel [5]. Tanzania Telecommunications Company Ltd (TTCL) [6] has coverage in some of the regions in Tanzania mainland. Others mobile operators such as Sasatel [7], Smile [8] etc are operating in major cities such as Dar es Salaam [9].

Fig. 1 shows subscription market share for different mobile carriers in Tanzania as in September 2014[10]. It can be observed that all companies are struggling to attract customers in their network. It has been said that Mobile Carrier that have succeeded in the past and that will continue to flourish in the era to come know that the future is brightest for Mobile Carriers that develop technologies that make the lives of customers easier and better. This means satisfying the needs and desires of people of all age groups, both in the work place and at home. While technologies continue to evolve, Mobile Carriers and equipment manufacturers must continue to build interoperable and highly flexible infrastructures, from the first mile to the last mile. This will open the door to a new era of barrier free and personalized options for communication and entertainment. The possibilities are endless with the growth of mobile Carriers/Operators the customers are challenged to choose a proper network operator.

Table 1: Mobile Phone and Fixed line in Tanzania [10]

\begin{tabular}{c|c|c|c|}
\hline YEAR & FIXED LINES & MOBILE & TOTAL \\
\hline 2000 & 173,591 & 110,518 & 284,109 \\
\hline 2001 & 177,802 & 275,557 & 453,359 \\
\hline 2002 & 161,590 & 606,859 & 768,449 \\
\hline 2003 & 147,006 & $1,298,000$ & $1,445,006$ \\
\hline 2004 & 148,360 & $1,942,000$ & $2,090,360$ \\
\hline 2005 & 154,420 & $2,963,737$ & $3,118,157$ \\
\hline 2006 & 151,644 & $5,609,279$ & $5,766,566$ \\
\hline 2007 & 163,269 & $8,322,857$ & $8,486,126$ \\
\hline 2008 & 123,809 & $13,006,793$ & $13,130,602$ \\
\hline 2009 & 172,922 & $17,469,486$ & $17,642,408$ \\
\hline 2010 & 174,511 & $20,983,853$ & $21,158,364$ \\
\hline 2011 & 161,063 & $25,666,455$ & $25,827,518$ \\
\hline 2012 & 176,367 & $27,450,789$ & $27,627,156$ \\
\hline 2013 & 164,999 & $27,442,823$ & $27,607,822$ \\
\hline Sept. 2014 & 150,149 & $30,430,460$ & $30,580,609$ \\
\hline & & & \\
\hline
\end{tabular}

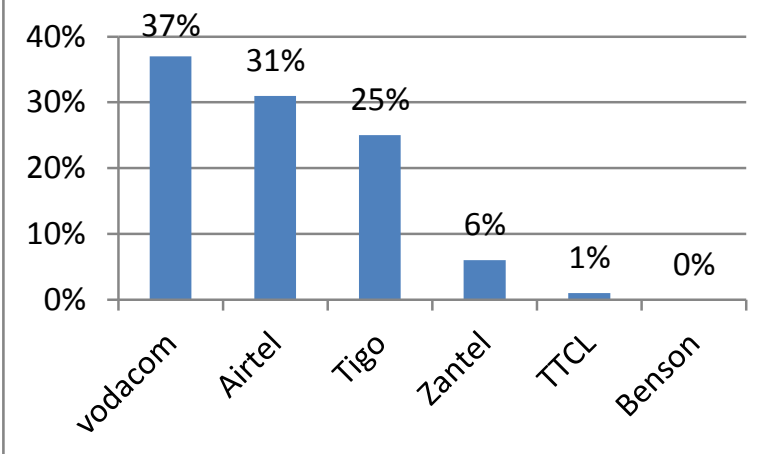

Fig. 1: Mobile subscription market share in Tanzania [10]

This paper is a series of our study on the consumer preferences in selection of mobile carrier. In Anatory and Manase[11], looked at tariff influence customer preference in selection of mobile operators. It was revealed that the tariff influence customers by $61 \%$. In addition, Anatory and Manase [12], studied network effects and Quality of services (QoS) 
influence customer preference in selection of mobile operators. It was revealed that network coverage had the highest influence which is $68.8 \%$, followed by QoS which is $64.9 \%$. This paper investigates consumer preferences for Mobile Carriers looking at Group, Family, Age and Gender as contributing factors. For comparison purpose of the same area and group studied in [11 and 12] were used.

\section{EMPIRICAL FRAMEWORK 2.1 Groups as a Consumer Preference for Mobile Carrier}

Groups that have a direct influence on a person's behaviour and to which a person belongs are called membership groups. There are primary and secondary groups; Primary group is the group with whom there is a regular but informal interaction such as family, friends, neighbours, and fellow workers, while secondary groups are the groups which are more formal and have less regular interactions such as religious groups, professional associations and trade unions. Reference groups can influence a person in at least three ways: They expose the person to new behaviours and lifestyles. They influence the person's attitudes and self-concept because he wants to fit in. They create pressure to conform that may affect the person's product and brand choices. The importance of the group influence varies across products and brands, but it tends to be strongest for conspicuous purchases. A product can be conspicuous for two reasons: It may be noticeable because very few people own it. The buyer of that conspicuous product consumes it in public where others can see it.

In most cases, a person buying a very luxurious product will generally be influenced strongly by others. Birke and Swann [13] studied consumer behaviours in choosing mobile operators by testing groups of students from United Kingdom (UK), Malaysia, Netherlands and Italy, surveying the students about their friends within the class and about their use of the mobile phones. The first study that was conducted at the Nottingham University Business School found that there was a strong coordination of mobile phone operators among friends. They deduced that friends are more than twice as likely to have the same operator as the two randomly picked students. The tendency was true also for overseas students who went to UK for studies and who were to choose a mobile operator when they arrived in the UK [13].

\subsection{Family as a Consumer preferences for Mobile Carrier}

Members of the buyer's family can exercise a strong influence on the buyer's behaviour. Two families can be distinguished in buyer's life. The buyer's parents make up the family of orientation. They provide a person with an orientation towards religion, politics and economics, and a sense of personal ambition, self-worth and love. Even if the buyer no longer interacts very much with his or her parents, the latter can still significantly influence the buyer's behaviour. The families of procreation- the buyer's spouse and children have a more direct influence on everyday buying behaviour.

This pattern of a family results in a nuclear family, consisting of parents and children living together, and also in an extended family, which include the nuclear family as well as aunts, uncles, grandparents, and in-laws. All of these people influence buyer's lives and their buying behaviour. Marketers are interested in the roles and relative influence of the husband, the wife and children on the purchase of a large variety of products and services [14]. In their findings, Kotler et al[14] emphasized that, the behaviour of various family members at each stage of the purchasing decision is of major importance to marketers. Birke and Swann [13] in their study on effects of family influence in selection of mobile operator concluded that, the choice of a mobile operator is strongly coordinated within households and that the effect is far stronger than the effect of overall network size.

\subsection{Age as a Consumer Preference for Mobile Carrier}

People change the goods and services they buy over their lifetimes. Marketers often define their market in life-cycle stage terms and develop appropriate products and marketing plans. According to Stanton and colleagues, marketers should also pay attention to the changing consumption interest that might be associated with these adult passages [15], point out that the age of a consumer can have a significant impact on their behaviour. The age of a consumer generally indicates what products he/she may be interested in purchasing or which media they are exposed to. In their study, Lamb et $a l[16]$ indicated that many college students are young people with their own unique needs, and therefore suggested that marketers need to keep the youthfulness of students in mind when developing their promotional strategies and product strategies. The youths get bored easily and constantly look for new, innovative products and communication themes. They prefer information given to them directly and although they value friendship, as seen by their use of friends as shopping companions, they want to be treated as individuals. This sense of individuality is also clear from the fact that they mainly make use of their own past experience as a source of information, and do not necessarily buy the same products or brands as their friends or family members. This current study will consider the age of university students as being between 20 years to 45 years and also consider their gender to find out if there is any significant relationship between student's age, and/or gender and selection of mobile operators.

\subsection{Gender as a Consumer Preference for Mobile Carrier}

While biological and physical differences define the sexual differences between male and female, the term gender relates to the set of arrangements by which a society transforms biological sexuality into products of human activity and in which these transformed needs are satisfied [17]. Decision considerations and self-image in men's and women's impulse purchases indicated that gender differences are pronounced in orientations towards sets of material goods [18]. By comparison, women saw their possessions as important because of the emotional comfort they provide and the relationships with others they symbolize. Dittmar et al [18] suggested for more research to establish whether different types of objects and different types of considerations are also important to women and men at the point of purchase. The same researchers in their other study, found out that, men tend to impulsively buy instrumental and leisure items projecting independence and activity, while women tend to buy symbolic and self-expressive goods concerned with appearance and emotional aspects of self [18]. The current study would like to establish whether the same men and female characteristics apply in selection of mobile operators.

Another study by Kotler et al[14] noted that husband-wife involvement in purchasing varies widely by product and category and by stage in the buying process. The buying role changes with evolving consumer lifestyle. While almost everywhere in the world, the wife is traditionally the main purchasing agent for the family, especially in the areas of 
household products, food and clothing, to date, with more than 60 per cent women holding jobs outside the home in developing countries, and the willingness of some husbands to do more of the family purchasing, all the traditional behaviour is changing [15]. A survey conducted for Finnish young people aged 16-20 years found that mobile phone usage was consistent with respondent's general consumption styles [18]. The study showed that addictive usage of mobile phones was common among females and was related to trendy and impulsive consumption. The study concluded that genders are becoming more alike in mobile phone choice.

Knowledge on how gender relates to the purchase decision is of interest in the academic since in many product categories, women make the purchase decisions [19]. In her study on the impact of Internet user shopping patterns and demographics on consumer mobile buying behaviour. Sanz[19] observed that the influence of gender on specific behaviour of the shoppers is complex. Social-cultural pressure has made men generally more independent in their purchase decisions, while women place greater value on personal contact and social relations. The society has traditionally favoured affective relations among women, for example, the development of shared activities with adults of the same sex, entails greater interdependency in their social relations.

In contrast, Sanz[19] noted that, men need to develop their own identity, even if it means repressing their affective and relational needs. These schemes of interdependency and separation do not only influence the individual's personality, but also his or her attitude and behaviour towards different situations such as shopping. Thus, Sanz[19] noted that, men's purchase motivations are usually mainly utilitarian. Many women consumers see shopping as a source of stimulation and inspiration and place special value on the act of shopping [19]. Empirical studies show that family members play a significant part in influencing buyer's decision in purchase of products or services.

\section{RESEARCH METHODOLOGY}

\subsection{Research Design}

The study on Age, Family, Group and Gender as consumers' preferences in selecting their mobile carrier combined both quantitative and qualitative approach, based on cross-sectional survey design. This is a survey in which observation of sample is done at one point in time and the data collected provides the description of population feature. Normally cross-sectional survey studies focus on the relationship between different variables and relates to how they affect each other at the same time [20]. This type of design was chosen because it enables to describe the different factors that influence consumer preference in selecting their mobile carrier, and make predictions based on the correlational survey data. Other advantages of cross-sectional survey design it gives the opportunity to see the reality more closely; inferences are not based on theory or dogma, but on facts as observed from the collected data. It is more objective and it helps to know the social situation around the target population. It is a practical way of collecting information such as attitudes, opinions, experiences and expectations from the population and it sensitizes the researcher to unanticipated or unknown problems. It facilitates to draw generalizations about population on the basis of data from representative sample. It is useful in verifying theories. Finally, it is for these advantages that the study opted for it.

\subsection{Area of Study and its Characteristics}

Dodoma Region is located at Latitude $6^{\circ} 10^{\prime} 60 \mathrm{~S}$ and Longitude $35^{\circ} 45^{\circ} \mathrm{OE}$, and at an Altitude of 1,148 meters above sea level. This region is located at the centre of Tanzania. Dodoma region has a population of over 1.7 million, out of which, 48.4 percent are males and 51.6 percent are females [11]. The region has a land area of 41,311 square kilometers and a population of $1,692,025$ according to National Census, 2002[12]. Dodoma region is selected as a case for this study to represent all other regions in Tanzania due to the fact that, all of the giant mobile operators conducting mobile phone business in Tanzania are found in Dodoma. The other main reason for selection of Dodoma is for the convenience of the researcher who is living in and working in Dodoma Municipality [21].

Dodoma population has drastically increased in the past three years due to opening of two Universities, namely: The University of Dodoma (a public University)[22], and The St. John's University of Tanzania (privately owned by Anglican Church of Tanzania)[10]. Other high learning Institutions within the municipality have been upgraded to offer degree programs. These are: The Institute of Rural Development and Planning (IRDP), and College of Business Education (CBE) [10]. Together, these changes have drastically increased the population of the municipality, creating new business opportunities in the mobile telephony industry. Started only seven years ago, St. John's University of Tanzania has already enrolled more than 2,500 students while UDOM, having the same age as St. John's University approached 20,000. CBE has more than 2600 students. Since most of the students are youths and coming direct from secondary schools, most of them would like to own mobile phones immediately upon their arrival at the Colleges/Universities.

\subsection{Target Population, Sampling Techniques and Sample Size}

All Tanzanians using mobile phones are eligible respondents of the study. However, it is not economically wise or possible to reach out them all so as to generate the sample frame for the study. Hence, the current study picked students from institutions of higher learning to represent a segment of all mobile users in Tanzania. Having four colleges of the kind, namely, The University of Dodoma, College of Business Education, St. John's University College of Tanzania, and The Institute of Rural Planning and Development, two colleges have been picked to represent the rest. UDOM and the $\mathrm{CBE}$ were the picked institutions.

The current study used both non-probability and purposive sampling techniques to get the required information from the study population. Purposive sampling technique was used to select Dodoma Municipality, and specifically UDOM and CBE. While non-probability sampling techniques, particularly quota sampling and straw ball sampling method was used to get the respondents.

In purposive sampling, researchers select respondents according to their convenience [23]. It was sometimes necessary to pick some students well know to own mobile phones and request them to participate in responding to the questionnaire. Different sampling methods were used to minimize the effects of misrepresentation of the population that could have resulted from non probability sampling method employed in this study.

Under this method, individuals select themselves as participants [24]. In this case, when one participant volunteer 
to answer the questionnaires, they were be asked if they knew any other students with mobile phones and who could also participate in responding to the questionnaires. Questionnaires were distributed to about 80 students, out of which 50 were from UDOM and 30 from CBE. Equal number of females and males were given the questionnaires from each college.

\section{DATA COLLECTION METHODS}

To gather the primary data for this study, close-ended questionnaires were distributed to fifty UDOM students and thirty students from CBE. Close-ended questionnaire were preferred in this study because, such questions are easy to administer and usually evoke a rapid response. Since the respondents are higher learning institution students who are most of the time bombarded with workloads from their academic syllabuses, great care was taken to ensure that the type of questions asked to them do not consume a lot of their time in responding, lest they lose interest and give up.

\subsection{Negotiating Access to Data Collection and Research Ethics}

Concert of the respondents was vital prior to data collection exercise. Therefore, students were persuaded to participate in responding to the questionnaires and asked if they knew some friends who owned mobile phones and who would also be willing to participate in the research. Where an approached student was not willing to participate, their decisions were humbly respected. The respondents were assigned anonymous numbers, (codes) instead of using their names, and even the institutions were also assigned codes. The dully filled questionnaires were locked under safe custody later after entering data into computer.

\subsection{Reliability and Validity of the Research}

Reliability of a questionnaire is the ability of the questionnaire to give the same results when filled out by like-minded people in similar circumstances. Reliability is usually expressed on a numerical scale from zero (very unreliable) to one (extremely reliable). It is mainly concerned with whether the measure used in a research will yield the same results in different occasions, or if it can provide similar observations if done in different occasions [25]. Reliability of a research, according to Kirakowski[25] may suffer from the following threats:

To ensure validity of the collected data in the current study, the questionnaires were pre-tested to students of other high learning institutions and all ambiguous and unclear questions were corrected. The researcher ensured that respondents could understand the questions and answer them without assistance of the researcher. The recorded questionnaires were collected by the researcher to avoid any manipulation to the data already filled in the questionnaires. The same were kept under safe custody in a locked cabinet. To further ensure the reliability and validity of the measurements, this study used standard scales such as Likert scale for attitude test and well structured close-ended questionnaires.

\subsection{Methods of Data Analysis and Presentation}

The study on factors which influence mobile phone customers in selecting their mobile operators used different statistical techniques that include descriptive analysis and multiple logistic regressions to test the relationships between dependent variable (selection of a mobile phone operator) and the independent variables namely: tariff, network coverage, quality of service, groups (such as friends and family members), age and gender. This information was analyzed using Statistical Package for Social Science (SPSS) Software.

Logistic regression was used in analyzing the data because it is among many statistical techniques that can establish relationships between a dependent variable and multiple independent variables. The independent variables are dichotomous and for this case, logistic regression is the best statistical analysis method that fits the type of data. The technique could also analyze any non-linear relationships between dependent and independent variables. Other advantages of logistic regression according to Statgun Statistic Consulting [26] are: It is more robust: the independent variables don't have to be normally distributed, or have equal variance in each group. It does not assume a linear relationship between the independent variables and dependent variable. The dependent variable need not be normally distributed. There is no homogeneity of variance assumption. Normally distributed error terms are not assumed. It does not require that the independents be interval. It does not require that the independents be unbounded [26].

Regression analysis is used to produce an equation that will predict a dependent variable (selection of mobile network operator), using the specified independent variables (tariff, network coverage, quality of service, groups-family members or friends, age and gender).

\section{PRESENTATION AND DISCUSSION OF RESULTS}

The data being presented in this part are the responses from the questions that were given to respondents from two higher learning institutions. The two higher learning institutions are UDOM and CBE which were selected to represent the particular population. The study intended to find out whether there is a relationship between selection of mobile operator and groups, (such as family members and friends), age and gender. Out of the 80 questionnaires distributed to respondents, 77 which constitute $96.25 \%$ were received. It was indicated that at least all questionnaires distributed to female students were received back, while $92.5 \%$ of the questionnaires distributed to male students were received back. Table 2 shows respondent's subscription to existing mobile carriers. It can be observed that, currently Vodacom had more subscribers within the sampled population than any other mobile network operator, having 32 subscribers, which accounts $41.6 \%$ out of all respondents.

Table 2: Respondent's Subscription to Existing Mobile carriers

\begin{tabular}{|c|c|c|}
\hline Operator & $\begin{array}{c}\text { Number of } \\
\text { Respondents }\end{array}$ & Percentage \\
\hline Vodacom & 32 & 41.6 \\
\hline Tigo & 16 & 20.8 \\
\hline Airtel & 7 & 9 \\
\hline TTCL & 2 & 2.6 \\
\hline Vodacom and Tigo & 9 & 11.7 \\
\hline Vodacom and Airtel & 1 & 1.3 \\
\hline
\end{tabular}




\begin{tabular}{|c|c|c|}
\hline Vodacom and TTCL & 2 & 2.6 \\
\hline Airtel and Tigo & 4 & 5.2 \\
\hline Tigo and TTCL & 1 & 1.3 \\
\hline $\begin{array}{c}\text { Airtel, Tigo, Vodacom } \\
\text { and Zantel }\end{array}$ & 1 & 1.3 \\
\hline Zantel and Vodacom & 1 & 1.3 \\
\hline Tigo and Zantel & 1 & 1.3 \\
\hline Total & $\mathbf{7 7}$ & $\mathbf{1 0 0 . 0}$ \\
\hline
\end{tabular}

The second position was taken by Tigo, $(20.8 \%)$, and then Airtel, (9\%). TTCL had the minority market share, when compared to the first three giant mobile operators, with only $2.6 \%$. The rest was a combination of the multiple subscriptions to various operators. A critical case was also observed where one subscriber was subscribed to four different mobile network operators. For this particular sampled population, no subscriber was found to be subscribed to Zantel alone. This might be due to the operator being not so popular in Tanzania mainland so far.

\subsection{Consumer Preference for Mobile Carrier and Group}

From theoretical framework, some consumers make their buying decisions due to the influence from family members and friends [14]. The current study wanted to investigate whether or not the respondent's selection of their current mobile operator was influenced by any of their family members. The results indicate that $51.9 \%$ of respondents agreed to be influenced by family members into subscription to their mobile operators, while $40.25 \%$ of the respondents disagreed. Only $7.8 \%$ of the respondents were neutral about this question. The results indicate that, 41 respondents $53.2 \%$ of the respondents agreed to be influenced by friends into selecting their mobile operators, while $31.2 \%$ of respondents disagreed to be influenced by friends. $15.6 \%$ of the respondents were neutral about this question. This study wanted to establish how many of the respondent's family members, especially parents or friends were connected into the same mobile network. A total of 36 respondents which is $46.8 \%$ had all of their parents subscribed into the same mobile network, while 36 respondents which is $46.8 \%$ had their parents subscribed into different mobile networks. Five of the respondents which constitute $6.5 \%$ of total respondents said that none of their parents were subscribed in the same mobile network.

When the data was regressed using the SPSS, the test results are not statistically significance since the significance level is 0.562 which is far greater than 0.05 , which is the acceptable level of significance. We therefore cannot reject the null hypothesis at this level of significance. The Beta coefficient is seen to be 0.067 and it is negative, an indication that family members have a negative relationship with selection of a mobile network operator. Its implication is that, for this sampled population, the more the numbers of family members in one network, the lesser the probability of the particular operator to be selected. The possibility of operator selection decreases by $6.7 \%$ for every increase of one family member into that particular mobile network. However, the test was not statistically significant.

The statistical relationship between friends and selection of a mobile operator was investigated by regression the collected data on mobile operator and influence from friends. Results indicate that the test is not statistically significant. The level of significance is 0.562 which is also too big to reject the null hypothesis. Due to the results of the two test, we therefore accept the null hypothesis that, "There is no relationship between family members and friends and selection of a mobile network operator". Both family members and friends fall in the category of 'Group influence', according the theories on Consumer buying behavior [27]. From the study results, although data for family influence were collected separately from data for friend's influence, their corresponding levels of significance after regression are the same. The standardized Beta coefficients have equal magnitudes except that, the relationship between selection of a mobile operator and family members is negative while that for friends is positive.

These statistical results concur with findings by Raghuram et al[28] who conducted a research in Korea to find out whether friends had influence in social purchases[28]. The result of their study revealed that, $48 \%$ of their study sample had no significant impact of friends on their purchase decisions, while $40 \%$ had a positive change in purchase decisions due to influences from friends. $12 \%$ of the respondents reduced their purchase probabilities due to their friends purchase activities in the previous period. Raghuram et al [28] deduced that groups can be categorized into 3 groups namely, A group with positive change in probability due to social influence; A group with negative change in purchase probability due to social influence; A group with no effect. According to Raghuram et al [28], moderate users of any commodity have positive social effect in purchase probability and are of moderate status. These people would like to maintain their status, and they counted to $40 \%$ in their study. The groups with negative change are the high status group who could opt to drop their choice just because other people have also opted for it. They counted to $12 \%$. The groups with zero effect were the low status group which counted to $48 \%$ of their sampled population. The group with zero effect contains members who are not well connected to other members as well as show little non-purchase related activity. These are essentially members who are assumed to visit very few members and likewise, very few visit them. In the current study 'family influence' can be categorized in the group with negative change in purchase probability due to social influence, while 'friends influence' can be categorized in group with positive change. However, the statistical test was not significant.

These statistical results contradict with the results of a similar study conducted at the Nottingham University in UK by Birke and Swann [13], where it was revealed that students had a strong coordination of mobile operators among friends, but a much stronger effect is the operator choice of other household members. They also contradict the theory by Kotler et al [14] on consumer buying behavior which emphasizes that there is a strong influence from groups in making purchase decisions [14]. Other researchers who had similar findings are Doganoglu and Grzybowski [29], who deduced that the spread of mobile services within an individual's social circle may influence selection of a mobile operator. Other research findings by Mitomo deduced from his almost similar study conducted in Beijing, Hong Kong and Taipei that mobile 
customers tend to choose a mobile phone operator by word of mouth from family members and friends [30].

\subsection{Selection of Mobile Carrier and Age}

The ages of respondents spanned from 20 years to 44 years. The ages were transformed into two groups namely, junior customers (20-30 years), and senior customers (31-50) years. The study on consumer preferences in selection of their mobile carrier wanted to know if there is any relationship between customer's age and the selection of a mobile carrier. The results show that majority of the respondents which is $81.8 \%$ belonged to the junior customers group, while the minority respondents were in the senior customers group, which is $18.2 \%$. When respondent's ages were regressed with the selection of mobile operator, the results indicated that Sig. $=0.421$. This test results is not statistically significant since it is very big compared to the specified significance level, (Sig. $=0.05$ ). We therefore accept the null hypothesis that, "There is no relationship between age and selection of mobile network operator".

The Beta coefficient is -0.093 , indicating a negative contribution of age towards prediction of selection of a mobile operator, and it accounts for only $9.3 \%$. This coefficient signifies that, if all other predictors are kept constant, as the age of the respondent increases, the probability of mobile operator selection decreases by $9.3 \%$. However the test was not statistically significant.

The study results concur with findings by Rogers [31] who conducted a study on socioeconomic characteristics in America. Rogers [31] revealed that, there is inconsistence relationship between age and adoption of innovations. From his study, a few showed that earlier adopters of any innovations are those of young age while some indicated that early adopters are those of older ages. In general Rogers concluded that attractions and appreciations of technological changes, (of which mobile communication falls within the class), has a negative relationship with age. The older the age, the more unlikely the customer is to adopt new technological changes, or switch from one mobile operator to the other due to changing of one attribute of the particular mobile network operator [31].

The findings differ from the results of a similar study conducted by Lamb and colleagues in Ohio where it was concluded that, consumer's age can have a significant impact on their buying behavior [16]. Lamb and colleague conducted the research among students and came up with findings that, many college students are young people with their own unique needs hence they get bored easily and constantly look for new, innovative products and communication themes. The results also contradict with consumer buying behavior theories by theorists like Kotler et al [27], and Belch and Belch [32]. According to Kotler et al [27], and Belch and Belch [32], age is among the personal effects which affect how consumers make their buying decisions and other buying behaviours.

The findings can be explained that, subscription and usage of mobile phones has been extensive in all age groups. The volume of usage can be different according to customer's purchasing power or the financier's purchasing power, but not according to the customers age. With the current stiff competition among the mobile phone industry, still with extensive promotions and bonus, all age groups are capable of subscribing into even more than one mobile operator.

\subsection{Gender and Selection of Mobile Carrier}

The theory of consumer buying behaviour believes that, decision consideration and self-image in men's and womenls impulse purchases indicate that gender differences are pronounced in orientation towards sets or material goods [33]. The current study wanted to investigate whether there is any relationship between gender and selection of mobile network operator. During data collection, this study intended to have equal numbers of female and male respondents. Unfortunately, during the survey, the number of male students who were ready to participate was not as big as intended. Out of 80 respondents intended for the study, with equal distribution of 40 respondents from each category, the number of male respondents was $37,(92.5 \%)$ while female respondents were $40,(100 \%)$. Hence out of 77 respondents who participated in the research, $52 \%$ were females, while the remaining $48 \%$ were males.

Regression analysis of the gender information with selection of mobile operator yielded the results shown that, the test is not statistically significance since significance level is 0.571 , too big compared to the reference significance level of 0.05 . The null hypothesis cannot be rejected at this level of significance. We therefore accept the null hypothesis that, "There is a no relationship between gender and selection of mobile network operator". The Beta coefficient is 0.066 , meaning that, gender predict selection of a mobile operator by $6.6 \%$. However, the test was not statistically significant.

These results concur with the results obtained by Hao et al [34], in their study on how to improve customer loyalty in Chinese Mobile Telecom Market. They revealed that gender had no influence on customer's selection of a mobile operator, or satisfaction to one mobile operator, and hence, customer's decision to switch from one mobile operator to the other depended on other attributes [34].

The results contradict the theoretical framework on consumer behaviour as stipulated by Kotler et al [27] that, people of different sex respond differently to advertisements and promotions into making purchase decisions even at the same category of purchases. There being no relationship between selection of a mobile operator and gender is also contrary to findings by other researchers such as Dittmar et al [33]. Wilska [35], and Sanz[36] who studied consumer buying behaviour to different groups and came up with results that gender was one of the influencing factors in customer's purchasing decisions. Dittmar et al [33] found out from their studies that while men tend to impulsively buy instrumental and leisure items projecting for independence and activity, women tend to buy symbolic and self-expressive goods concerned with appearance and emotional aspects of self. Sanz[36] on her part for example, observed that the influence of gender on specific behaviour of the buyers is complex. As per Sanz[36], gender influence in some specific behaviour such as mobile phone subscription and usage is complex. The difference between female and male customers in selection of mobile operators is mostly noted on the factors that influence each of them in making subscription decisions. Factors like free SMS, bonuses on recharging and free calls or discounted calls are much more pronounced in female customers than in male customers. Wilska [35] had noted from his study that females were easily addicted in mobile phone usage than men. The small percentage of prediction of selection of a mobile network operator as shown in Table 22 due to gender influence can be explained as among the complex behaviour in customer subscription to mobile networks. 


\section{CONCLUSION}

The current study was conducted on students in higher learning institutions and it was revealed through descriptive analysis that, the influence of the independent variables in selection of mobile carrier was the least influencing factor was groups, which countered only $45.5 \%$. The age and gender influence was not as direct as the other factors. Nevertheless statistical analysis had different results for the other independent variables in that, there was no enough evidence to reject the null hypotheses for there being no relationship between selection of a mobile operator and groups, age and gender. Statistical analysis was based on a decision rule that, the null hypothesis would be accepted or rejected with reference to $p$-value, the significance level of the particular test statistics. Where the p-value was less than the selected significance level which is 0.05 , the null hypothesis was rejected. Otherwise, the null hypothesis was accepted.

It is known from consumer behaviour theory that, some products or services are acquired due to their quality in the eyes of buyers or from the post-purchase assessment. A satisfied buyer is therefore likely to repurchase the product or service, and also is likely to recommend it to a friend [14]. This can also be supported by the fact that, with the best quality of service, mobile customers acquired extra lines from other mobile operators so as to compensate for other attractive attributes from other operators. The mobile customers can therefore use their mobile telephones interchangeably while compromising for the required attribute at the particular time of usage.

It was concluded from this study that, there was no relationship between selection of a mobile operator and groups, such as family members and friends. When respondents were asked about how many of their family members and friends were connected in the same mobile network like themselves $8 \%$ had none of their friends in the same network, while $25.3 \%$ had less than half of their friends in the same network. This scenario leads into a conclusion that, although theories on consumer buying behaviour believe that there is a strong relationship between groups and consumer buying decision, influence of groups in mobile phone subscription among the study population was not a strongest influencing factor. The impact of the influence will be stronger if other factors such as quality of service are attractive. However, this phenomenon may change depending on the social class of the customers or the ages of the customers, since the bond between family members, say, parents, guardians or siblings is stronger at junior age than it will be at middle age, while a bond between friends may be stronger at middle and senior age than at advanced age [36]. The negative coefficients of Beta obtained while analyzing the relationship between selection of mobile operator and family members, and also between selection of mobile operator and age were contradicting with many other researchers who did similar studies before. The Beta coefficients for both family members and age have negative signs. The case for family members was supported by Raghuram et al [28] while the case of age was supported by Rogers [37].

According to 60 respondents, $78 \%$ are likely to recommend their current mobile operator to a friend, while 5 respondents, $(6.3 \%)$ are unlikely to recommend their mobile operators to a friend. As Kotler et al [14] mentioned, a satisfied customer is likely to recommend the product or service to friend. The results of the responses indicate that, most of the customers were happy with the services they were receiving from their mobile operators and hence, they were ready to recommend them to their friends. It is very important for the operators to device some means to establish how satisfied with their services their customers are, since the reverse is dangerous for their business reputation.

When asked about how satisfied the respondents were with the services they were receiving from their current mobile operators, the response showed that $71.5 \%$ of the respondents were satisfied with the service received from their mobile operators, while $10.4 \%$ were not satisfied. Out of all 77 respondents, $16.9 \%$ were neutral on how they felt about the service received from their mobile network operators, while $1.3 \%$ had nothing to say about the service. This is an indication that, mobile operators have to work on how to retain their customers through customer satisfaction after acquiring them into their networks since failure to do so may cause the customers to switch from one network to another, or accumulate a number of telephone lines which turn out to be churns, from the operator's point of view.

Although the study found out that $71.5 \%$ were satisfied with the services they were receiving from their operators, yet $78 \%$ indicated that they were likely to recommend their current operators to a friend. This means that, even those who did not either care to say something about how they felt about the services they were receiving, or those who were neutral were still ready to recommend their mobile operators to a friend. This is where the influence of friends can result into potential customer's subscription decision. A word of mouth is a strong influence at times rather than advertisements [37].

\section{RECOMMENDATIONS}

The study revealed that some customers would like to have time to discuss with their mobile carriers so that they could air their advice to them for service improvement. The current study offered an opportunity to the respondents with the aim of learning the grievances among subscribers, although the grievances might not be serious enough to lead to customer churn away or abandonment of the service. Most of the interviewed respondents wanted to advice their mobile carriers to improve their network coverage and reduce tariffs. Some wanted more offers such as free calls at some times of a day, and cheap rates for short messaging. Only one respondent wanted the operators to offer education to their customers, but two of them also advised on improved customer care. This information is necessary for mobile carriers so that they can address the shortfalls for their customer retention.

This study also revealed that, students in higher learning institutions are opportunists who are ready to migrate from one mobile operator to another, or subscribe to as many mobile network carriers as possible, as long as they find some attractive attributes with a new operator. Although they recharge their mobile phone with small denomination vouchers, they do it repeatedly such that their average monthly usage become very high compared with many other ordinary mobile customers. Knowing this fact, mobile operators can develop special and attractive packages to this particular market segment and yet realize a sound profit from this market. 


\section{SUGGESTIONS FOR FUTURE STUDIES}

This study has come up with a conclusion that, there is no statistical relationship between groups, age and gender, and selection of mobile carrier. Unfortunately the kind of tests conducted could not establish the reasons or causes for these results. The results are contradicting with the theory on consumer buying behaviour in general purchases. For this case, the results obtained here cannot be generalized in a wider population or a population of a different type. We therefore call for other researchers to study on a wider population in Tanzania to get mobile customers from different fields of life so as to help in verifying whether this is a true and a peculiar behaviour for Tanzanian mobile telecommunication market or it was unique for the type of population picked in this study.

\section{REFERENCES}

[1] Chintan S. (2012), "Consumer Preferences for mobile service providers: An Empirical Study in Bardoli", International Journal of Marketing and Technology, Vol. 2, Issue 8, pp. 269-288.

[2] Vodacom Tanzania Ltd, https://www.vodacom.co.tz/, site visited on 24/02/2015.

[3] Tigo Tanzania, http://www.tigo.co.tz/, site visited on 26/02/2015.

[4] Airtel Tanzania, http://www.africa.airtel.com/wps/wcm/connect/africarev amp/Tanzania/ site visited on 24/02/2015.

[5] Zantel Tanzania, http://www.zantel.co.tz/, site visited on $16 / 9 / 2014$.

[6] TTCL, http://www.ttcl.co.tz/, site visited on 24/02/2015.

[7] Sasatel Tanzania, http://www.sasatel.co.tz., site visited on $24 / 02 / 2015$

[8] Smile Tanzania, http://smile.co.tz/\#page. Site visited on $16 / 9 / 2014$

[9] Dar es Salaam, http://www.dsm.go.tz/. Site visited on $24 / 02 / 2015$

[10] Tanzania Communications Regulatory Authority (TCRA), http://www.tcra.go.tz, accessed 24/02/2015.

[11] Anatory, J. and Ekael S. M. (2014), "Tariff as a Determining Factor in Choosing Mobile Operators: A Case Study from Higher Learning Institution in Dodoma Municipality in Tanzania", International Journal of Social, Management, Economics and Business Engineering Vol. 8, No.4, pp. 1190-1197.

[12] Anatory J. and Ekael S. M.( 2014), "Network Effects and QoS as a Determining Factors in Selection of Mobile Operator: A Case Study from Higher Learning Institution in Dodoma Municipality in Tanzania", International Journal of Social, Management, Economics and Business Engineering Vol.8, No.10, , pp. 3197-3203.

[13] Birke, D., Swann G. M. P. (2006), "Mobile Phones: How Mobile Consumers Choose their Operator", Journal of Evolutionary Economics, Vol.14 No.17, 3-4.

[14] Kotler, P., Armstrong G., Saunders J. and Wong V., (1999), "Principles of Marketing, Consumer Buyer Behaviour, $2^{\text {nd }}$ European Edition, Prentice Hall International (UK).
[15] Stanton, W.J., Etzel, M.J and Walker, B.J., (1994), Fundamentals of Marketing, $10^{\text {th }}$ Ed. New York: McGraw-Hill, Inc.

[16] Lamb, C.W., Hair, J. F. and McDaniel, C. (2004), Marketing, $7^{\text {th }}$ Edition, Ohio, South Western.

[17] Birke, D., Swann G. M. P. (2006), "Network Effects and the Choice of Mobile Phone Operator", Journal of Evolutionary Economics, Vol. 16, No. 1-2, 65-84.

[18] Cellular News, (2003), "Telecom Growth Driven by Mobile Connection”, Unpublished report, Indian Cellular Association's, India.

[19] Shaughness, John, J., Zechmeister, Eugene, B., and Zechmeister Jeanne, S (2002), "Research Methods in Psychology", Mc Graw-Hill Companies.

[20] Dodoma Municipal, www.dodoma.go.tz, accessed, $30 / 12 / 2014$

[21] The University of Dodoma, www.udom.ac.tz, accessed, $30 / 12 / 2014$

[22] Lohr, S.L. (1999), "Sampling: Design and Analysis, Duxbury Press, Pacific Grove, CA.

[23] Creswell, J. W. (1994), "Research Design: Qualitative and Quantitative Approaches" Sage Publications Thousand Oaks, CA.

[24] Kirakowski, Jurek, (2000), "Questionnaires in Usability Engineering", Unpublished Report, Human Factors Research Group, Cork, Ireland.

[25] Statgun Online Dictionary, [http://www.statgun.com/tutorials/logisticregression.html site- visited on $24 / 2 / 2015$.

[26] Kotler, P., Armstrong G., Saunders J. and Wong V., (1999), "Principles of Marketing, Consumer Buyer Behaviour, $2^{\text {nd }}$ European Edition, Prentice Hall International (UK).

[27] [28] Raghuram, I., Sangman, H., Sunil, G. (2009), "Do Friends Influence Purchases in a Social Network?" [http://www.hbs.edu/research/pdf/09123.pdf] site visited on $25 / 2 / 2015$.

[28] Doganoglu, T. and Grzybowski L., (2006), "Estimating Network Effects in Mobile Telephony in German", Centre for Information and Network Economics, University of Munich, [http://www.lrzmuenchen.de/ grzybowski/de-moboles.pdf], site visited on $25 / 02 / 2015$.

[29] Mitomo H., Liqiao W., Otsuka T., (2005), "Mobile Communication and Asian Modernities", MSc Thesis, Waseda University, Japan.

[30] Rogers, M. (1995), "Diffusion of Innovations, (4th Edition), the Free Press, A Division of Simon and Schuster Inc., 1230 Avenue of the Americas, New York, NY 10020.

[31] Belch, GE and Belch MA (2007), "Advertising and Promotion: An Integrated Marketing Communication Perspective", $7^{\text {th }}$ edition, McGraw Hill/Irwin, New York.

[32] Dittmar H., Jane B., and Susanne F., (1995), "Gender Identity and Material Symbols: Objects and Decision 
Considerations in Impulse Purchases". Journal of Economic Psychology, Vol.6, No. 15, 391- 511

[33] Yi, H., Xiaoqin, Y., Weiqing, Z., (2009), "How to Promote Customer Loyalty of Chinese Mobile Telecom Operator: Case Study of Chinese Mobile", [http://www.bth.se] site visited on 24/3/2015.

[34] Wilska, T. A (2003), "Mobile Phone Use as Part of Young People's Consumption Styles". Journal of Consumer Policy, Vol. 26, No. 4, 441-463.
[35] Sanz, Silvia, (2005), "The Impact of Internet User Shopping Patterns and Demographics on consumer Mobile Buying Behaviour", Publication, Journal of Electronic Commerce Research.

[36] Kotler, Phillip, (2000), "Marketing Management”, Prentice Hall International (UK).

[37] Enrique B., Carla R., Silvia S., (2005), “The Impact of Internet User shopping patterns and Demographics on consumer mobile buying behavior", Journal of Electronic Commerce Research, VOL. 6, NO.3, pp. 193-209. 